\title{
Transaortic correction of tetralogy of Fallot and similar defects
}

Arkalgud Sampath Kumar, MCh, Sachin Talwar, MCh, and Devagourou Velayoudam, MCh, New Delhi, India

Supplemental material is available online.

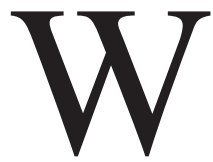

e present a new approach to the correction of tetralogy of Fallot (TOF) and similar defects. Two adult patients, one with TOF and one with ventricular septal defect (VSD) and infundibular pulmonary stenosis (PS), underwent repair of these defects through an aortotomy incision and are reported here.

\section{Patients and Technique}

PAtient 1. A 30-year-old man presented with typical features of TOF. His arterial oxygen saturation was $71 \%$. His angiogram demonstrated the cardiac morphology. On May 4, 2005, he underwent intracardiac repair.

Cardiopulmonary bypass was established with aortic and bicaval cannulation. After aortic crossclamping, the first dose of cardioplegia was delivered antegrade through the aortic root. The patient was cooled to $32^{\circ} \mathrm{C}$. A transverse aortotomy incision was made just $1 \mathrm{~cm}$ distal to the right coronary artery. A 6-0 polypropylene suture was placed through the corpora arantii of the noncoronary and right coronary cusps and retracted with a rubber-shod hemostat. The VSD was large and clearly visualized along all its margins (Figure E1). The infundibular ostium was visualized through the VSD (Figure 1). A 4-0 braided polyester suture was placed on the infundibular ostium, which was enlarged by dividing the hypertrophied muscle bands around it. On completion of resection of the septal band the index finger was passed freely into the infundibular chamber as far as the pulmonary annulus.

The VSD was closed using a Polytetrafluoroethylene (Gore-Tex, Flagstaff, Ariz) patch with interrupted 5-0 polypropylene sutures. Sutures were placed under direct vision, and in the area of the bundle of His they were placed through the base of the tricuspid septal leaflet.

From the Department of Cardiothoracic and Vascular Surgery, All India Institute of Medical Sciences, New Delhi, India.

Received for publication Nov 30, 2005; accepted for publication Dec 12, 2005.

Address for reprints: A. Sampath Kumar, Department of Cardiothoracic and Vascular Surgery, All India Institute Of Medical Sciences, New Delhi-110029 (E-mail: asampath_kumar@hotmail.com).

J Thorac Cardiovasc Surg 2006;131:1185-6

$0022-5223 / \$ 32.00$

Copyright () 2006 by The American Association for Thoracic Surgery doi:10.1016/j.jtcvs.2005.12.029
On completion of these 2 steps the aortotomy was

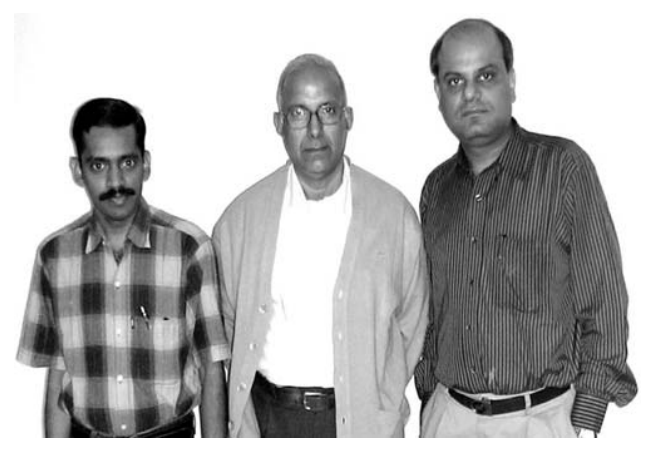

Drs Devagourou, Kumar, and Talwar. (left to right).

patient was rewarmed, and the aortic crossclamp was removed. The heart was defibrillated and began beating in sinus rhythm. A pericardial patch was used to enlarge the hypoplastic main pulmonary artery from the annulus to its bifurcation and to excise calcium from the patient's stenotic pulmonary valve. Cardiopulmonary bypass was discontinued with satisfactory correction with no residual intracardiac shunt. The patient's postoperative right ventricle/left ventricle pressure ratio was 0.5 . Cardiopulmonary bypass time was 118 minutes, and aortic crossclamp time was 96 minutes.

PAtient 2. A 24-year-old man with predominant dyspnea on exertion was found to have a large VSD with infundibular PS (Figure E2, Figure 2). The gradient across the right ventricular outflow tract (RVOT) was $90 \mathrm{~mm} \mathrm{Hg}$. He had no cyanosis.

On October 21, 2005, the patient underwent infundibular resection and closure of the VSD through an aortotomy incision as described above. No pericardial patch was required for the RVOT. His postoperative right ventricular systolic pressure was $35 \mathrm{~mm}$ $\mathrm{Hg}$, with a systemic arterial pressure of $77 \mathrm{~mm} \mathrm{Hg}$. A postoperative transesophageal echocardiography confirmed a good repair.

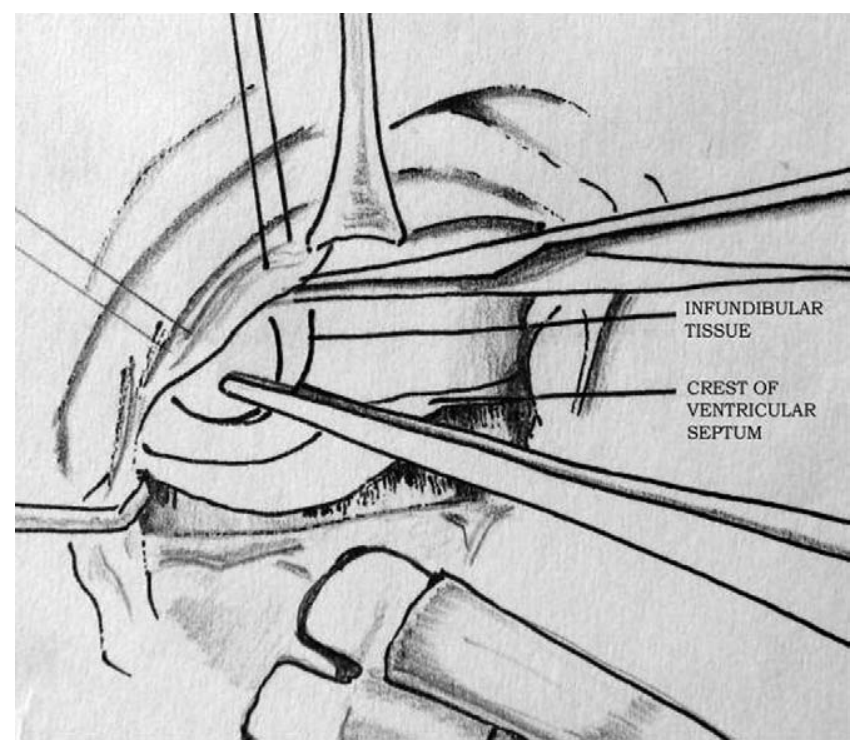

Figure 1. Line drawing of surgical view of the defect in first patient. 


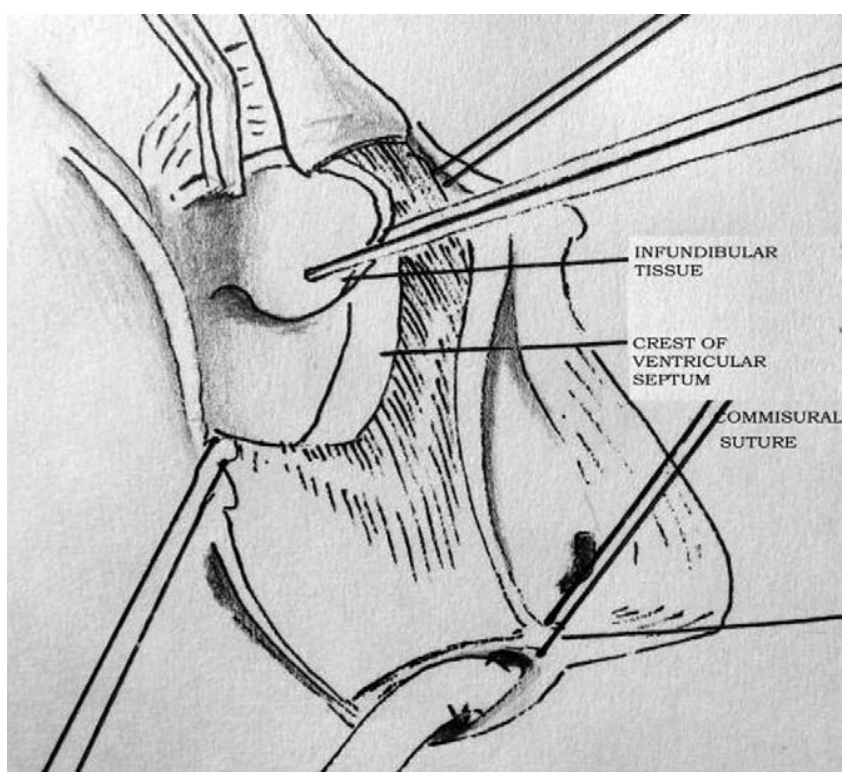

Figure 2. Line drawing of surgical view of the defect in second patient.

The first patient was seen in the outpatient clinic 5 months after surgery during the first week of October. A transthoracic echocardiography demonstrated satisfactory repair. Both patients are doing well with New York Heart Association class 1 and have no significant gradients across the RVOT.

\section{Comment}

To our knowledge a transaortic approach to the correction of these defects (TOF/VSD+PS) has not been described earlier in the English literature. There are only 2 reports $^{1,2}$ on the transaortic approach for other conditions. In both our patients the aortic root was large, with a large VSD directly below it. The infundibular obstruction is immediately downstream of the large VSD and can be easily visualized and adequately resected. Gentle traction on the aortic wall of the infundibular chamber will bring the pulmonary valve annulus into view. There is no fear of injury to the aortic cusps or the bundle of His because the visualization of the VSD by this approach is exceptional. In addition, arrhythmias that may occur after a transventricular repair are entirely avoided. We believe this approach can be used in selected patients for a total correction. The advantages are excellent visualization of the defects and avoidance of injury to the aortic cusps and bundle of His. In addition, placement of the VSD patch on the left ventricular outflow side may prevent residual shunts after repair.

The authors thank Dr. Venkataiya for the line drawings.

\section{References}

1. Harlan BJ, Cooley DA. Transaortic repair of double outlet right ventricle with situs versus, 1-loop, 1-malposition (1,L,L), subaortic ventricular septal defect, and associated anomalies. J Thorac Cardiovasc Surg. 1976;72:547-52.

2. Watanabe T, Sabai Y, Song MH, Shinomura T, Tajima K, Yasuura K. Transaortic approach for closure of residual ventricular septal defect of the tetralogy of Fallot. Ann Thorac Cardiovasc Surg. 1999;5:254-57. 


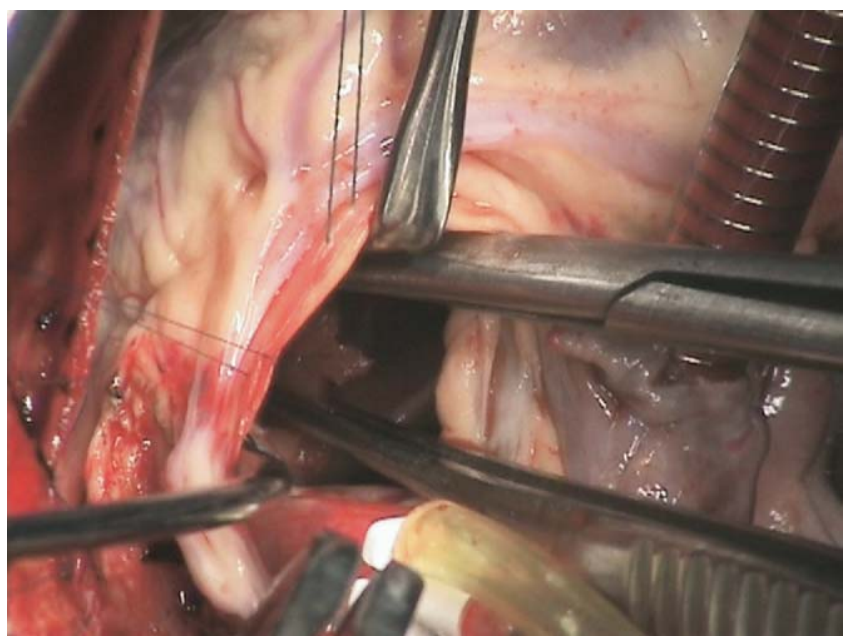

Figure E1. Operative photograph of first patient.

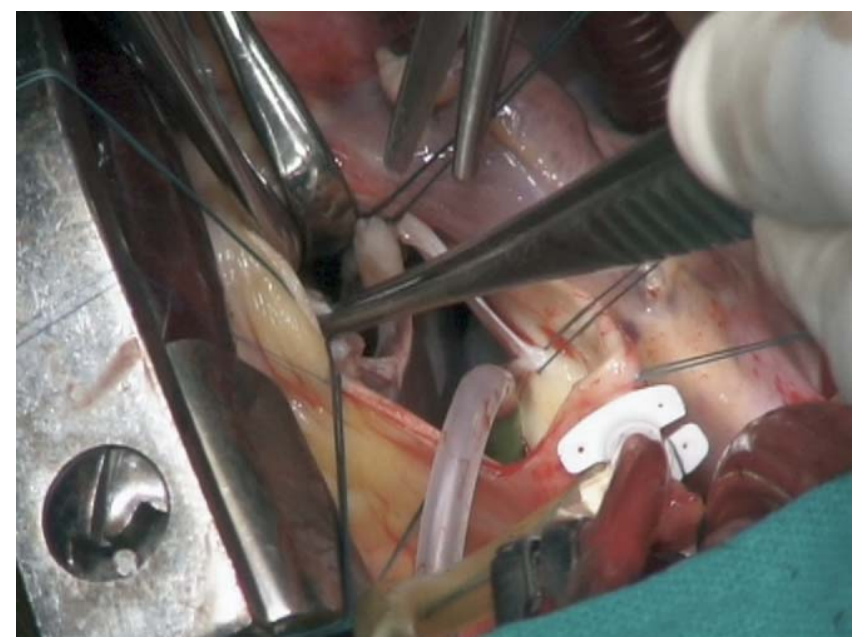

Figure E2. Operative photograph of second patient. 